\title{
Hepatic Intracellular Distribution of Tritium-labeled Unconjugated and Conjugated Bilirubin in Normal and Gunn Rats*
}

\author{
Leslie H. Bernstein, $\dagger$ Judith Ben Ezzer, Lawrence Gartner, $\$$ And \\ IRWIN M. ARIAS § \\ (From the Department of Medicine, Albert Einstein College of Medicine and the Bronx \\ Municipal Hospital Center, New York, N.Y.)
}

Relatively little is known about the mechanism, regulation, or subcellular localization of the hepatic uptake, storage, conjugation, and excretion of bilirubin. In the work here reported, the ultrastructural localization of the sites of these processes was studied by determining the subcellular distribution and chemical nature of bilirubin after the injection of physiologic amounts of tritiumlabeled unconjugated bilirubin $\left(\mathrm{UCB}-{ }^{3} \mathrm{H}\right.$ ) and conjugated bilirubin $\left(\mathrm{CB}^{-} \mathrm{H}\right)$ in normal and glucuronyl transferase-deficient (Gunn) rats (1, $2)$. Studies were also performed using bilirubin${ }^{14} \mathrm{C}$ for comparison with the intracellular distribution of tritiated bilirubin. While these studies were in progress, Brown, Grodsky, and Carbone (3) described the subcellular distribution of injected $\mathrm{UCB}-{ }^{3} \mathrm{H}$ in normal rat liver.

\section{Methods}

Tritium-labeled bilirubin was prepared by the Wilzbach procedure and purified and equilibrated with crystalline bovine albumin to constant specific activity as described by Grodsky, Carbone, Fanska, and Peng (4). The purity of labeled bilirubin was established by diazotization, chro-

* Submitted for publication January 28, 1966; accepted April 5, 1966.

These studies were supported by research grants from the U. S. Public Health Service (AM 02019 and TI AM 5384) and the New York Heart Association and Heart Fund, Inc.

This work was presented in part at the Eastern Section Meeting of the American Federation for Clinical Research, New York, N. Y., November 1964.

$\dagger$ Formerly U. S. Public Health Service trainee in gastroenterology.

$¥$ Special Fellow of the National Institute of Child Health and Human Development (2 F3. HD-23,073).

$\S$ Address requests for reprints to Dr. Irwin M. Arias, Dept. of Medicine, Albert Einstein College of Medicine, Eastchester Rd. and Morris Park Ave., Bronx, N. Y. 10461. matography (5), and strip scanning of the resulting azo pigments. The azo pigments were not extracted, and all of the radioactivity in the original bilirubin solution migrated with the unconjugated azo pigment (Azo-A) on paper chromatograms.

Male Wistar and Gunn rats weighing 300 to $400 \mathrm{~g}$ were maintained on Purina rat chow and anesthetized with pentobarbital ( $50 \mathrm{mg}$ per $\mathrm{kg}$ ) injected intraperitoneally. Polyethylene catheters ( $\mathrm{PE} \mathrm{50)}$ were placed in the jugular vein and common bile duct. UCB- ${ }^{3} \mathrm{H}$ (50 to $75 \mu \mathrm{g}$ containing $1.5 \times 10^{7} \mathrm{dpm}$ ) was rapidly dissolved in $0.5 \mathrm{ml}$ of $0.1 \mathrm{M}$ sodium bicarbonate; the $\mathrm{pH}$ was adjusted to 7.8 with $0.1 \mathrm{~N} \mathrm{HCl}$, and an equal volume of rat serum was added. During this procedure bilirubin was protected from light. The UCB- ${ }^{3} \mathrm{H}$ solution was then rapidly injected intravenously.

Bile obtained from normal rats injected with $\mathrm{UCB}-{ }^{3} \mathrm{H}$ was stored at $-20^{\circ} \mathrm{C}$ for not more than 48 hours before use and served as a source of $\mathrm{CB}-{ }^{8} \mathrm{H}$. Chromatography and subsequent strip scanning of azo pigments obtained from this bile revealed 82 to $96 \%$ of the total radioactivity in bile to migrate with the conjugated azo pigment (Azo-B) on paper chromatograms. The mean specific activity of $\mathrm{CB}-{ }^{8} \mathrm{H}$ was $60 \%$ of $\mathrm{UCB}-{ }^{3} \mathrm{H}$, and accordingly 85 to $125 \mu \mathrm{g}$ containing $1.5 \times 10^{7} \mathrm{dpm}$ was used in each experiment.

Bilirubin- ${ }^{14} \mathrm{C}$ was prepared according to the technique of Ostrow, Hammaker, and Schmid (6) and was recrystallized to a constant specific activity of $0.91 \mathrm{mc}$ per mmole.

At intervals of 1 to 60 minutes after injection of UCB- ${ }^{8} \mathrm{H}, \mathrm{UCB}-{ }^{14} \mathrm{C}$, or $\mathrm{CB}-{ }^{3} \mathrm{H}$, a single lobe of the liver was removed, maintained at $0^{\circ} \mathrm{C}$, rinsed in $0.25 \mathrm{M}$ sucrose at $\mathrm{pH} 7.4$, blotted dry, weighed, and homogenized in a Teflon glass homogenizer containing 9.0 vol of the buffered sucrose solution. The order in which lobes were removed was varied in initial experiments, but no significant difference in uptake of radiobilirubin among different lobes was observed.

Eight normal rats were injected with $\mathrm{UCB}-{ }^{8} \mathrm{H}$, and total intrahepatic radioactivity was estimated in homogenates of liver obtained at $1,2,4,8,9,15,30,45$, and 60 minutes after injection. Twenty studies of the subcellular distribution of radiobilirubin were performed using liver obtained from these rats at intervals from 1 to 60 minutes after injection of $\mathrm{UCB}-{ }^{8} \mathrm{H}$. Three normal 
TABLE I

Per cent of total hepatic enzyme activity in subcellular fractions*

\begin{tabular}{|c|c|c|c|c|c|}
\hline Fraction & $\begin{array}{l}\% \text { of total } \\
\text { cytochrome } \\
\text { oxidase }\end{array}$ & $\begin{array}{c}\% \text { of total } \\
\text { acid } \\
\text { phosphatase }\end{array}$ & $\begin{array}{l}\% \text { of total } \\
\text { glucose 6- } \\
\text { phosphatase }\end{array}$ & $\begin{array}{l}\text { \% of total } \\
\text { glucuronyl } \\
\text { transferase }\end{array}$ & $\begin{array}{l}\% \text { of total } \\
\text { protein } \\
\text { content }\end{array}$ \\
\hline $\begin{array}{l}\text { Nuclear } \\
\text { Mitochrondrial } \\
\text { Lysosomal } \\
\text { Microsomal } \\
\text { Supernatant } \\
\text { Total }\end{array}$ & $\begin{array}{r}7.8 \pm 3.1 \\
38.2 \pm 4.1 \\
30.1 \pm 2.4 \\
18.2 \pm 7.6 \\
0.0 \\
94.3 \pm 8.4\end{array}$ & $\begin{array}{r}5.4 \pm 2.1 \\
10.7 \pm 4.6 \\
50.3 \pm 8.1 \\
20.9 \pm 6.2 \\
5.2 \pm 3.1 \\
92.5 \pm 7.3\end{array}$ & $\begin{array}{r}2.3 \pm 1.5 \\
3.3 \pm 4.1 \\
12.2 \pm 3.3 \\
72.1 \pm 8.0 \\
7.1 \pm 3.1 \\
97.0 \pm 5.6\end{array}$ & $\begin{array}{r}1.4 \pm 0.9 \\
7.1 \pm 3.9 \\
17.5 \pm 3.8 \\
67.1 \pm 4.8 \\
6.9 \pm 4.1 \\
98.6 \pm 8.3\end{array}$ & $\begin{array}{r}24.6 \pm 1.1 \\
7.0 \pm 3.8 \\
5.2 \pm 3.1 \\
30.2 \pm 4.0 \\
28.0 \pm 3.1 \\
98.0 \pm 3.2\end{array}$ \\
\hline
\end{tabular}

* Each figure is the mean \pm standard deviation of ten determinations in five normal and five Gunn rats except glucuronyl transferase activity, which was estimated in only five normal rats.

rats were injected with $\mathrm{UCB}-{ }^{14} \mathrm{C}$, and total radioactivity and subcellular distribution of radiobilirubin were estimated in lobes of liver obtained at $1,5,10,30,45$, and 60 minutes after injection.

Two normal rats each weighing $310 \mathrm{~g}$ were injected intravenously with unconjugated bilirubin (7) at a rate of $0.2 \mathrm{mg}$ per minute for 1 hour, at which time $50 \mu \mathrm{g}$ of UCB- ${ }^{8} \mathrm{H}$ (containing $1.5 \times 10^{7} \mathrm{dpm}$ ) was rapidly injected intravenously. Fifteen minutes later hepatectomy was performed. The total hepatic bilirubin concentration was determined in a $10 \%$ homogenate according to Hargreaves (8); subcellular fractions were prepared, and distribution of radioactivity was determined.

Seven Gunn rats were injected with $\mathrm{UCB}-{ }^{3} \mathrm{H}$, and total intrahepatic radioactivity was estimated in homogenates of liver obtained at $2,4,8,12,15,45$, and 60 minutes after injection. Seven studies of the subcellular distribution of radiobilirubin were performed using liver obtained from these rats at intervals from 1 to 60 minutes after injection of $\mathrm{UCB}-{ }^{8} \mathrm{H}$.

CB- ${ }^{8} \mathrm{H}$ was injected in four normal rats and four Gunn rats. Six studies of the subcellular distribution of radiobilirubin were performed at intervals of 1 to 60 minutes in each group.

For study of the distribution of UCB- ${ }^{3} \mathrm{H}$ and $\mathrm{CB}-{ }^{3} \mathrm{H}$ in subcellular fractions in vitro, two normal and two Gunn rats were anesthetized with pentobarbital and killed by decapitation. The livers were flushed through the portal vein with isotonic saline at $0^{\circ} \mathrm{C}$, weighed, and made up to $10 \%$ homogenates in buffered $0.25 \mathrm{M}$ sucrose. A dose equivalent to one-half the injected dose of UCB- ${ }^{3} \mathrm{H}$ (25 to $30 \mu \mathrm{g})$ or $\mathrm{CB}-{ }^{8} \mathrm{H}$ (45 to $65 \mu \mathrm{g}$ ) was added to the chilled homogenate in the homogenizing vessel. This was again passed rapidly under the pestle and allowed to stand for 30 minutes at $0^{\circ} \mathrm{C}$. Fractionation, enzymatic assays, and counting of radioactivity were then performed.

Cell fractionation was performed at $4^{\circ} \mathrm{C}$ in buffered $0.25 \mathrm{M}$ sucrose according to Novikoff and Heus (9). To assure complete collection of the lysosomal fraction, we resuspended the poorly packed fluffy layer that begins to form during the second mitochondrial spin, and collected it with the succeeding lysosomal fraction. The efficiency of fractionation was determined in five normal and five Gunn rats by the following assays. Mitochondrial separation was estimated by cytochrome oxidase activity with cytochrome c and $N, N$-dimethyl-p-phenylenediamine (10). Lysosomal separation was evaluated by acid phosphatase activity with $p$-nitrophenyl phosphate (11). Portions were exposed to $0.5 \%$ Triton in glycine buffer $\mathrm{pH} 4.5$ containing $0.1 \mathrm{M}$ alloxan to inactivate selectively free acid phosphatase activity (12). Samples were then incubated at $\mathrm{pH} 4.5$ for 30 minutes to destroy glucose 6-phosphatase, which is also active in hydrolyzing this substrate (13). Microsomes were assayed for glucose 6-phosphatase activity (14) and, in the normal rats, for glucuronyl transferase activity with 4-methyl umbelliferone as the glucuronide receptor (15).

Protein was determined by the method of Lowry, Rosebrough, Farr, and Randall with crystalline bovine albumin as a standard (16). Scintillation counting was performed in a Nuclear Chicago series 720 liquid counting system. All samples $(100 \mu 1)$ were digested in $1 \mathrm{ml}$ of $10 \%$ solution of methanolic Hyamine ${ }^{1}$ and then dissolved in scintillation fluid. Correction of observed radioactivity for quenching was determined by plotting the decreasing efficiency of a toluene $-{ }^{3} \mathrm{H}$ sample, serially quenched with increasing amounts of pyridine, against the changing ratio of an appropriate two channel system. Bilirubin $-{ }^{14} \mathrm{C}$ was counted in a similar liquid counting system. Quench correction was determined by adding a known amount of toluene $-{ }^{14} \mathrm{C}$ as an internal standard and recounting all specimens. Chromatograms were scanned on a Vanguard model 880 strip scanner at an efficiency of $2 \%$.

$\mathrm{UCB}-{ }^{3} \mathrm{H}$ and $\mathrm{CB}-{ }^{8} \mathrm{H}$ were recovered from microsomal, lysosomal, and supernatant fractions of liver homogenates by adding 100 to $250 \mu \mathrm{g}$ of nonradioactive conjugated and an equal amount of unconjugated bilirubin in phosphate buffer $\mathrm{pH} 7.8$ to 50 to $100 \mu \mathrm{l}$ of the freshly obtained cell fraction, coupling with sulfanilic acid, and subsequently diazotizing the pigment. Conjugated bilirubin was added as bile freshly obtained from rats injected intravenously with unconjugated bilirubin. The azo derivatives were separated by paper chromatography (5) and eluted with $0.1 \mathrm{~N}$ acetic acid, and radioactivity was counted as described. We estimated the proportion of conjugated to unconjugated bilirubin in each fraction assuming that all of the conjugated azo pigment (Azo-B) was derived solely from bilirubin diglucuronide.

\footnotetext{
1 Packard Instrument Co., La Grange, Ill.
} 


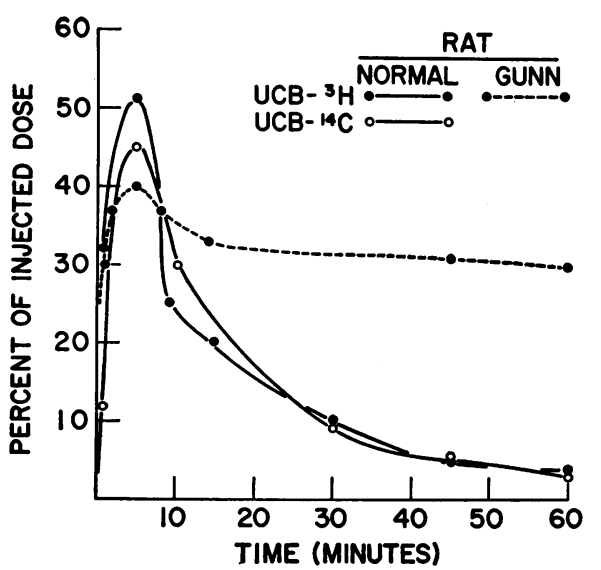

Fig. 1. Per cent of injected dose of unconjugated RADIOBILIRUBIN (UCB) IN THE LIVER OF NORMAL AND GUNn RATS AS A FUnCtion of TIME. Each point represents results obtained in either the whole liver or the initial lobe removed at the time stated in a single animal.

The turnover of radioactivity in lysosomes was studied in four normal rats injected with $\mathrm{UCB}-{ }^{8} \mathrm{H}$. A lobe of the liver was removed in each of two rats 1 and 4 hours after injection and in each of the other rats at 2 and 6 hours after injection. Liver homogenates were prepared, and the lysosomal fraction was separated as previously described. As a function of time, lysosomal radioactivity was expressed as per cent of injected dose as well as per cent of total intrahepatic radioactivity.

Student's $t$ test was used to calculate p values (17).

\section{Results}

The distribution of enzymes chosen to monitor the effectiveness of centrifugal fractionation is shown in Table I. Recovery was excellent. Mitochondrial separation, indicated by cytochrome oxidase activity, was almost evenly divided between the mitochondrial and lysosomal fractions. This results from efforts to assure complete collection of the lysosomal fraction by including the poorly packed fluffy layer that forms during the second mitochondrial centrifugation with the lysosomal fraction. The specific activity of acid phosphatase was increased ten times in the lysosomal fraction, and the specific activities of glucose 6-phosphatase and glycuronyl transferase were increased 2.4 times in the microsomal fraction.

$\mathrm{Up}$ to 5 minutes after the injection of $\mathrm{UCB}-{ }^{3} \mathrm{H}$ into eight normal rats, total intrahepatic radioactivity increased and subsequently decreased rapidly until at 1 hour less than $3 \%$ of the administered dose remained in the liver (Figure 1).
The subcellular distribution of radioactivity was not significantly different in 20 fractionation studies performed in liver obtained from 1 to $60 \mathrm{~min}$ utes after injection of $\mathrm{UCB}-{ }^{3} \mathrm{H}$ in these rats. The mean and standard deviation in the 20 studies of distribution of radioactivity in hepatic subcellular fractions are presented in Figure 2. The supernatant fraction contained $63 \pm 3.1 \%$ (SD) of intrahepatic radioactivity; the microsomal fraction contained $26 \pm 3.8 \%$ (SD), and the remaining $11 \%$ was almost evenly distributed among the other particulate fractions.

$\mathrm{Up}$ to 5 minutes after injection of $\mathrm{UCB}-{ }^{14} \mathrm{C}$ into three normal rats, total intrahepatic radioactivity increased and subsequently decreased rapidly until at 1 hour $3 \%$ of the administered dose remained in the liver (Figure 1). The subcellular distribution of radioactivity was not significantly different in six fractionation studies performed in liver obtained from 1 to 60 minutes after injection of $\mathrm{UCB}-{ }^{14} \mathrm{C}$. At all times the supernatant fraction contained $59 \pm 2.1 \%$ (SD) of total intrahepatic radioactivity; the microsomal fraction contained $24 \pm 3.5 \%$ (SD), and the remaining $17 \%$ was evenly distributed among the other particulate fractions. No significant differences were observed in the subcellular distribution of $\mathrm{UCB}-{ }^{3} \mathrm{H}$ and $\mathrm{UCB}-{ }^{14} \mathrm{C}$ in normal rat liver fractions.

After infusion of unlabeled UCB into two normal rats for 1 hour and subsequent injection of

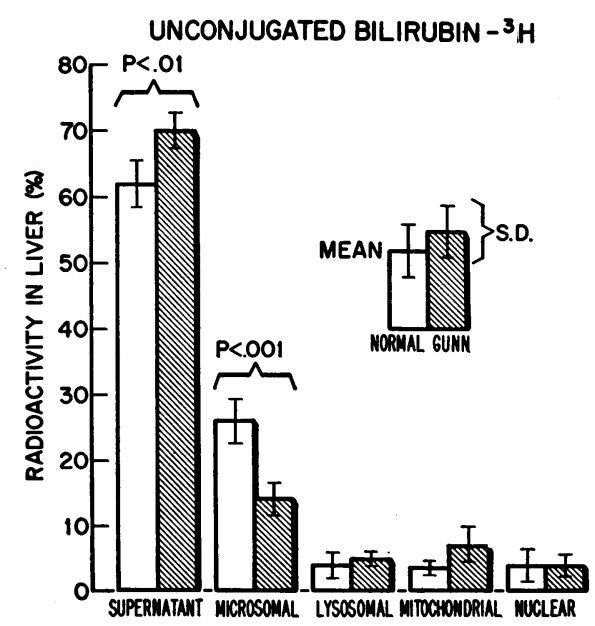

Fig. 2. Subcellular distribution of RadiobiliruBIN FROM 1 TO 60 MINUTES AFTER ADMINISTRATION OF UCB- ${ }^{3} \mathrm{H}$ TO NORMAL AND GUNN RATS. 
$\mathrm{UCB}-{ }^{3} \mathrm{H}$, the hepatic bilirubin concentrations were 5.6 and $7.1 \mathrm{mg}$ per $100 \mathrm{ml}$. Cell fractionation revealed 59 and $64 \%$ of intrahepatic radioactivity in the supernatant fraction, 22 and $26 \%$ in the microsomal fraction, and the remaining intrahepatic radioactivity distributed generally equally in the nuclear, mitochondrial, and lysosomal fractions.

$\mathrm{Up}$ to 5 minutes after the injection of UCB- ${ }^{3} \mathrm{H}$ into seven Gunn rats, total intrahepatic radioactivity increased to $40 \%$ of the injected dose, and at 1 hour $30 \%$ of the injected dose still remained within the liver (Figure 1). The subcellular distribution of radioactivity was not significantly different in seven studies of liver obtained from 1 to 60 minutes after injection of $\mathrm{UCB}-{ }^{3} \mathrm{H}$ in these rats. The mean and standard deviations are presented in Figure 2. Compared with liver fractions from normal rats, similar fractions from Gunn rats consistently revealed a greater percentage of total intrahepatic radioactivity in the supernatant fraction $[70 \pm 3.8 \%$ (SD), $\mathrm{p}>0.01$ ] and correspondingly less in the microsomal fraction $[16 \pm 3.6 \%$ (SD), $\mathrm{p}>$ $0.001]$.

In six studies performed in liver obtained from 1 to 60 minutes after injection of $\mathrm{CB}-{ }^{3} \mathrm{H}$ in four normal rats, the subcellular distribution of radioactivity was not significantly different from that observed in normal rats after injection of UCB- ${ }^{3} \mathrm{H}$ (Figure 3).

In six studies performed in liver obtained from 1 to 60 minutes after injection of $\mathrm{CB}-{ }^{3} \mathrm{H}$ in four Gunn rats, the subcellular distribution of radioactivity was not significantly different from that observed in normal rats after injection of either UCB- ${ }^{3} \mathrm{H}$ or $\mathrm{CB}-{ }^{3} \mathrm{H}$ (Figure 3 ).

Table II presents results of studies in vitro in

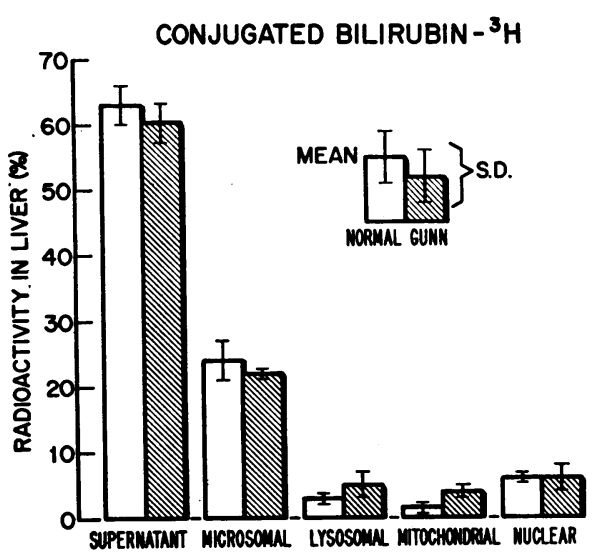

Fig. 3. Subcellular distribution of Radiobilirubin FROM 1 TO 60 MINUTES AFTER ADMINISTRATION OF CONJUGATED BILIRUBin (CB- $\left.{ }^{3} \mathrm{H}\right)$ TO NORMAL AND GUNN RATS.

which $\mathrm{UCB}-{ }^{3} \mathrm{H}$ and $\mathrm{CB}-{ }^{8} \mathrm{H}$ were separately added to homogenates of two normal and two Gunn rat livers before cell fractionation. The results were similar to those observed in the corresponding experiments in vivo. The microsomal fraction from Gunn rat liver contained significantly less $\mathrm{UCB}-{ }^{3} \mathrm{H}$ than did the microsomal fraction from normal rat liver. The supernatant fraction from Gunn rat liver contained significantly more $\mathrm{UCB}^{-3} \mathrm{H}$ than did the corresponding fraction from normal rat liver.

Attempts to recover radiobilirubin from cell fractions were made in two normal rats injected with $\mathrm{UCB}-{ }^{3} \mathrm{H}$, two normal rats injected with CB- ${ }^{8} \mathrm{H}$, and after separate addition of $\mathrm{UCB}-{ }^{3} \mathrm{H}$ and $\mathrm{CB}^{-3} \mathrm{H}$ to homogenates of two normal rat livers in vitro. The results are presented in Table III. After injection of UCB- ${ }^{8} \mathrm{H}$ or its addition in vitro, virtually no radioactivity was recovered in azo pigment $\mathrm{B}$ when microsomal, lysosomal, or

TABLE II

Per cent distribution of radioactivity in fractions of normal and Gunn rat liver after addition of unconjugated $\left(U C B-{ }^{8} H\right)$ and conjugated $\left(C B-{ }^{3} H\right)$ bilirubin in vitro

\begin{tabular}{|c|c|c|c|c|c|c|c|c|}
\hline \multirow[b]{3}{*}{$\begin{array}{l}\text { Nuclear } \\
\text { Mitochondrial } \\
\text { Lysosomal } \\
\text { Microsomal } \\
\text { Supernatant } \\
\text { Recovery }\end{array}$} & \multicolumn{4}{|c|}{ UCB-^H } & \multicolumn{4}{|c|}{ CB-^Н } \\
\hline & \multicolumn{2}{|c|}{ Normal } & \multicolumn{2}{|c|}{ Gunn } & \multicolumn{2}{|c|}{ Normal } & \multicolumn{2}{|c|}{ Gunn } \\
\hline & $\begin{array}{r}3 \\
3 \\
4 \\
24 \\
64 \\
98\end{array}$ & $\begin{array}{r}5 \\
6 \\
6 \\
28 \\
63 \\
108\end{array}$ & $\begin{array}{r}2 \\
3 \\
5 \\
12 \\
72 \\
94\end{array}$ & $\begin{array}{r}3 \\
4 \\
6 \\
14 \\
75 \\
102\end{array}$ & $\begin{array}{r}5 \\
4 \\
3 \\
23 \\
60 \\
95\end{array}$ & $\begin{array}{r}9 \\
4 \\
7 \\
25 \\
62 \\
107\end{array}$ & $\begin{array}{r}7 \\
5 \\
4 \\
22 \\
60 \\
98\end{array}$ & $\begin{array}{r}6 \\
5 \\
7 \\
23 \\
63 \\
104\end{array}$ \\
\hline
\end{tabular}


TABLE III

Recovery of radioactivity from cell fractions of normal rats after administration or addition of $U C B-{ }^{3} \mathrm{H}$ and $C B-{ }^{3} \mathrm{H}$

\begin{tabular}{|c|c|c|c|c|c|c|}
\hline \multirow{2}{*}{$\begin{array}{c}\text { Bilirubin } \\
\text { added }\end{array}$} & & \multirow{2}{*}{$\begin{array}{l}\text { No. of } \\
\text { animals }\end{array}$} & \multicolumn{4}{|c|}{$\begin{array}{l}\text { Per cent counts in } \\
\text { original cell frac- } \\
\text { tion recovered } \\
\text { from chromato- } \\
\text { grams of azo } \\
\text { derivatives }\end{array}$} \\
\hline & & & \multicolumn{2}{|c|}{ Azo-A* } & \multicolumn{2}{|c|}{ Azo-B* } \\
\hline \multirow[t]{4}{*}{ UCB-3H } & In vivo & & & & & \\
\hline & Supernatant & 2 & 67 & 50 & 0 & 0 \\
\hline & Microsomal & & 62 & 47 & 0 & 2 \\
\hline & Lysosomal & & 46 & 40 & 0 & 0 \\
\hline \multirow[t]{4}{*}{ UCB-³ } & In vitro & & & & & \\
\hline & Supernatant & 2 & 74 & 82 & $\mathbf{0}$ & $\mathbf{0}$ \\
\hline & Microsomal & & 66 & 70 & 0 & 0 \\
\hline & Lysosomal & & 59 & 54 & 0 & 0 \\
\hline \multirow[t]{4}{*}{$\mathrm{CB}-{ }^{-3} \mathrm{H}$} & In vivo & & & & & \\
\hline & Supernatant & 2 & 0 & 0 & 72 & 78 \\
\hline & Microsomal & & $\mathbf{0}$ & 4 & 76 & 85 \\
\hline & Lysosomal & & 0 & 0 & 55 & 69 \\
\hline \multirow[t]{4}{*}{ CB-s ${ }^{-3}$} & In vitro & & & & & \\
\hline & Supernatant & 2 & 0 & $\mathbf{0}$ & 87 & 75 \\
\hline & Microsomal & & $\mathbf{0}$ & 0 & 82 & 79 \\
\hline & Lysosomal & & $\mathbf{0}$ & $\mathbf{0}$ & 47 & 64 \\
\hline
\end{tabular}

*Azo-A = unconjugated azo pigment $;$ azo- $\mathrm{B}=$ conjugated azo pigment.

supernatant fractions were studied. After injection of $\mathrm{CB}-{ }^{3} \mathrm{H}$ or its addition in vitro, radioactivity was easily demonstrated in azo pigment $\mathrm{B}$. From $54 \%$ to $82 \%$ of added $\mathrm{UCB}^{3} \mathrm{H}$ and from $47 \%$ to $87 \%$ of added $\mathrm{CB}^{3} \mathrm{H}$ were recovered from cell fractions.

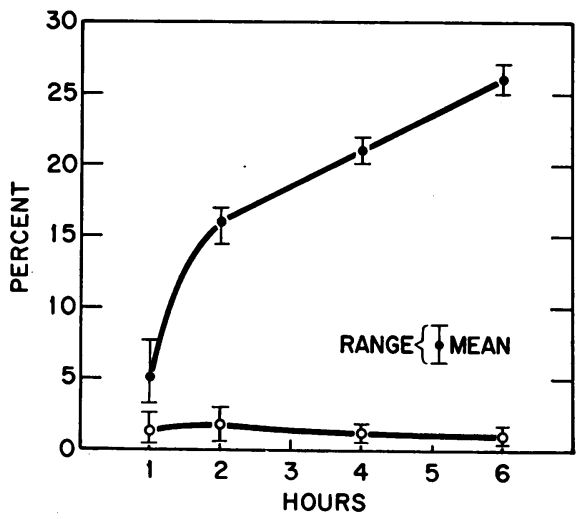

Fig. 4. InCORPORATION OF RADIOACTIVITy INTO THE LYSOSOMAL FRACTION OF LIVER HOMOGENATES FROM NORMAL RATS AFTER INTRAVENOUS ADMINISTRATION OF UCB- ${ }^{3} \mathrm{H}$. Radioactivity in the lysosomal fraction is expressed as per cent of total radioactivity in liver (-O) and as per cent of administered dose $(\mathrm{O}-\mathrm{O})$.
Studies of radioactivity in lysosomal fractions prepared from 1 to 6 hours after injection of $\mathrm{UCB}-{ }^{3} \mathrm{H}$ in four normal rats are presented in Figure 4. Lysosomal radioactivity expressed as per cent of administered counts remained constant from 1 to 6 hours, although the per cent of total intrahepatic counts found in the lysosomal fraction increased from $3 \%$ at 60 minutes to $26 \%$ at 6 hours.

\section{Discussion}

The use of isotopically labeled bilirubin has permitted study of the distribution and intracellular binding sites of the pigment at physiologic concentrations. Although bilirubin $-{ }^{14} \mathrm{C}$, which is prepared biologically, possesses the advantage of having its isotopic label incorporated in the carbon skeleton of the molecule, the Wilzbach procedure provides an inexpensive method for preparing bilirubin- ${ }^{3} \mathrm{H}$ of considerably greater specific activity. After equilibration as described by Grodsky and his colleagues (4), constant specific activity is obtained.

The radiopurity of $\mathrm{UCB}-{ }^{3} \mathrm{H}$ is supported by the recovery of all counts originally in $\mathrm{UCB}^{3} \mathrm{H}$ in the unconjugated azo pigment (Azo-A) zone of paper chromatograms. Stability of $\mathrm{UCB}-{ }^{3} \mathrm{H}$ in vitro is supported by the observation of virtually identical hepatic uptake and subcellular distribution of UCB- ${ }^{3} \mathrm{H}$ and $\mathrm{UCB}-{ }^{14} \mathrm{C}$ in normal rats. Brown and his associates (3) reported similar results using unlabeled bilirubin and $\mathrm{UCB}-{ }^{3} \mathrm{H}$.

We had hoped that serial removal of lobes of the liver after intravenous injection of $\mathrm{UCB}-{ }^{3} \mathrm{H}$ might demonstrate sequential transport through an intracellular chain of particles. These hopes were not realized. Although partial hepatectomy was performed as early as 1 minute after injection, the subcellular distribution pattern was already established and remained unchanged for at least 1 hour, at which time all but 3 to $5 \%$ of the labeled pigment had been excreted into the bile. This relatively invariable pattern revealed about $60 \%$ of radioactivity in the supernatant fraction, approximately $25 \%$ in the microsomal fraction, and the rest distributed equally among mitochondria, lysosomes, and nuclei. These findings in normal rats confirm the results of Brown and associates ( 3 ). 
Starch gel electrophoresis of the supernatant fraction of normal liver containing $U \mathrm{UCB}^{3} \mathrm{H}$ revealed that the pigment was not bound to albumin but to a soluble protein or liproprotein that did not enter the gel at $\mathrm{pH} 7$ to 8. (18). This observation is consistent with the conclusions of Brown and co-workers that transfer of UCB from plasma albumin into the liver cell is too rapid for an albumin-linked transfer (3).

In the present study bilirubin in the supernatant fraction was unconjugated. This observation suggests that after administration of physiologic amounts of bilirubin, hepatic storage occurs in the cytoplasm of the liver cell and that the stored pigment is unconjugated.

A significant difference was observed in the subcellular distribution of $\mathrm{UCB}-{ }^{3} \mathrm{H}$ in normal and Gunn rats. After injection of UCB- ${ }^{3} \mathrm{H}$ in Gunn rats or its addition in vitro, the distribution of radioactivity was significantly reduced in the microsomal fraction and correspondingly increased in the supernatant fraction. Infusion of unlabeled UCB to normal rats for 1 hour produced hepatic bilirubin concentrations similar to those observed in Gunn rats (19) ; however, the subcellular distribution of injected $\mathrm{UCB}-{ }^{3} \mathrm{H}$ did not differ from that observed in normal rats without prior bilirubin infusions. These observations suggest that reduced binding of $\mathrm{UCB}^{-} \mathrm{H}$ to the microsomal fraction in Gunn rats does not result from significant amounts of unlabeled unconjugated bilirubin being bound to the microsomal fraction and thereby limiting further binding of radiobilirubin. Furthermore, the hepatic subcellular distribution of $\mathrm{UCB}-{ }^{3} \mathrm{H}$ in Gunn rats did not significantly differ from 1 to 60 minutes after its injection. If unconjugated bilirubin were bound to microsomes in the liver of the Gunn rat, some equilibration and exchange with radiobilirubin during 1 hour might be anticipated. In view of these considerations, it is suggested that glucuronyl transferase, which is primarily located in the smooth endoplasmic reticulum of the microsomal fraction (20), may be a binding site for unconjugated bilirubin and influence its transfer from the cytoplasm to the smooth endoplasmic reticulum where conjugation occurs.

Previous studies have shown that Gunn and normal rats excrete injected conjugated bilirubin at the same rate (7). The present studies show no difference in hepatic subcellular distribution of $\mathrm{CB}-{ }^{3} \mathrm{H}$ in normal and Gunn rats.

After injection of $\mathrm{CB}-{ }^{3} \mathrm{H}$ in normal rats or its addition in vitro to homogenates of normal rat liver, $\mathrm{CB}-{ }^{3} \mathrm{H}$ was recovered from the various cell fractions (Table III), and the subcellular distribution of radioactivity was similar to that observed in normal rats after administration of $\mathrm{UCB}^{3} \mathrm{H}$ (Figure 2). These observations demonstrate that the various cell fractions are capable of binding conjugated bilirubin; however, after injection of $\mathrm{UCB}^{-}{ }^{3} \mathrm{H}$, which reproduces the physiologic situation, no $\mathrm{CB}^{-}{ }^{3} \mathrm{H}$ was recovered from these fractions. The technique that was used permitted recovery of $54 \%$ to $82 \%$ of added $\mathrm{UCB}^{3} \mathrm{H}$ and from $47 \%$ to $87 \%$ of added $\mathrm{CB}^{-3} \mathrm{H}$ (Table III). The failure to recover any Azo pigment $B$ from either the supernatant or microsomal fraction of normal rat liver after injection of UCB- ${ }^{3} \mathrm{H}$ suggests several possibilities: 1) after conjugation, bilirubin rapidly leaves the cell;2) conjugated bilirubin may be more strongly bound to cytoplasmic proteins than is unconjugated bilirubin and is not extracted during diazotization; or 3 ) conjugated bilirubin is degraded or hydrolyzed during cell fractionation or diazotization or both. The last two possibilities are unlikely in view of the ease with which conjugated bilirubin was recovered from subcellular fractions after its injection in vivo or addition in vitro.

The mechanism for the rapid cellular excretion of conjugated bilirubin is not clarified by this study. Although the participation of cellular organelles, particularly lysosomes, in bilirubin excretion by the liver has been suggested by electron microscopic observations $(21,22)$ and by Brown and associates (3), we were unable to demonstrate participation of lysosomes in excretory transport of conjugated bilirubin. Less than $7 \%$ of intrahepatic radioactivity was in the lysosomal fraction up to 1 hour after administration of $\mathrm{UCB}-{ }^{3} \mathrm{H}$ or $\mathrm{CB}-{ }^{3} \mathrm{H}$ to either normal or Gunn rats in vivo or after addition of the labeled bile pigments in vitro. Furthermore, the per cent of hepatic radioactivity found in the lysosomal fraction of normal rat liver after injection of $\mathrm{UCB}-{ }^{3} \mathrm{H}$ increased from 1 to 6 hours, although the per cent of administered radioactivity found in the lysosomal fraction re- 
mained constant. These observations indicate that rapid turnover of radiobilirubin in lysosomes is unlikely and does not play a role in excretory transport of bile pigment.

\section{Summary}

The hepatic uptake, storage, conjugation, and excretion of bilirubin were studied by determining its subcellular distribution after intravenous injection of tritium-labeled unconjugated bilirubin $\left(\mathrm{UCB}-{ }^{3} \mathrm{H}\right)$ and conjugated bilirubin $\left(\mathrm{CB}-{ }^{8} \mathrm{H}\right)$ to normal and glucuronyl transferase-deficient (Gunn) rats. UCB- ${ }^{14} \mathrm{C}$ was used in similar studies in normal rats.

Although liver fractions from normal rats were studied as early as 1 minute after administration of $\mathrm{UCB}-{ }^{8} \mathrm{H}, \mathrm{UCB}-{ }^{14} \mathrm{C}$, or $\mathrm{CB}-{ }^{3} \mathrm{H}$, the subcellular distribution was already established and remained unchanged for at least 1 hour, at which time over $95 \%$ of administered radiobilirubin was excreted in the bile. In normal rats after administration of $\mathrm{UCB}-{ }^{8} \mathrm{H}, \mathrm{UCB}-{ }^{14} \mathrm{C}$, or $\mathrm{CB}-{ }^{8} \mathrm{H}$, addition of UCB${ }^{8} \mathrm{H}$ or $\mathrm{CB}^{8} \mathrm{H}$ in vitro, or administration of UCB${ }^{3} \mathrm{H}$ after intravenous infusion of unlabeled UCB, approximately $60 \%$ of intrahepatic radioactivity was in the supernatant fraction, $25 \%$ was in the microsomal fraction, and the remainder was divided in the other cell fractions. A similar subcellular distribution was observed in Gunn rats after injection of CB- ${ }^{8} \mathrm{H}$ or its addition in vitro.

After injection of UCB- ${ }^{8} \mathrm{H}$ in Gunn rats or its addition in vitro, the distribution of radioactivity was significantly reduced in the microsomal fraction and correspondingly increased in the supernatant fraction.

After injection of $\mathrm{UCB}-{ }^{3} \mathrm{H}$ to normal rats, $\mathrm{CB}-{ }^{3} \mathrm{H}$ could not be recovered from cell fractions, although the technique permitted recovery from supernatant or microsomal fractions of 72 to $87 \%$ of $\mathrm{CB}^{8} \mathrm{H}$ either injected or added in vitro.

After injection of UCB- ${ }^{8} \mathrm{H}$ to normal rats, the absolute radioactivity in lysosomes remained constant for 6 hours, although the per cent of intrahepatic radioactivity in lysosomes increased.

These studies suggest that unconjugated bilirubin is transferred from plasma into the cytoplasm of the liver cell, where it is bound to protein or proteins other than albumin. Glucuronyl transferase may be a binding site for unconjugated bilirubin and influence its transfer from the cytoplasm to the endoplasmic reticulum, where conjugation occurs. Under physiologic conditions hepatic storage of conjugated bilirubin is not observed, and conjugated bilirubin is rapidly excreted from the cell by a process that does not appear to involve lysosomes.

\section{References}

1. Axelrod, J., R. Schmid, and L. Hammaker. A biochemical lesion in congenital, nonobstructive, nonhemolytic jaundice. Nature (Lond.) 1957, 180, 1426.

2. Arias, I. M. A defect in microsomal function in nonhemolytic acholuric jaundice. J. Histochem. Cytochem. 1959, 7, 250.

3. Brown, W. R., G. M. Grodsky, and J. V. Carbone. Intracellular distribution of tritiated bilirubin during hepatic uptake and excretion. Amer. J. Physiol. 1965, 207, 1237.

4. Grodsky, G. M., J. V. Carbone, R. Fanska, and C. T. Peng. Tritiated bilirubin: preparation and physiological studies. Amer. J. Physiol. 1962, 203, 532.

5. Schmid, R. The identification of "direct-reacting" bilirubin as bilirubin glucuronide. J. biol. Chem. 1957, 229, 881.

6. Ostrow, J. D., L. Hammaker, and R. Schmid. The preparation of crystalline bilirubin- $\mathrm{C}^{\mathbf{1 4}}$. J. clin. Invest. 1961, 40, 1442.

7. Arias, I. M., L. Johnson, and S. Wolfson. Biliary excretion of injected conjugated and unconjugated bilirubin by normal and Gunn rats. Amer. J. Physiol. 1961, 200, 1091.

8. Hargreaves, T. The estimation of bilirubin in liver. Clin. chim. Acta 1965, 11, 278.

9. Novikoff, A. B., and M. Heus. A microsomal nucleoside diphosphatase. J. biol. Chem. 1963, 238, 710.

10. Straus, W. Colorimetric determination of cytochrome $\mathrm{C}$ oxidase by formation of a quinonediimonium pigment from dimethyl- $p$-phenylenediamine. Biochim. biophys. Acta (Amst.) 1956, 19, 58.

11. Shibko, S., and A. L. Tappel. Acid phosphatase of the lysosomal and soluble fraction of rat liver. Biochim. biophys. Acta (Amst.) 1963, 73, 76.

12. Neil, M. W., and M. W. Horner. The acid-p-nitrophenyl phosphatase activity of adult guinea-pig liver subcellular fractions. Biochem. J. 1962, 84, $32 P$.

13. Beaufay, H., and C. de Duve. Le système hexosephosphatasique. IV. -Spécificité de la glucose-6phosphatase. Bull. Soc. Chim. biol. (Paris) 1954, 36, 1525.

14. De Duve, C., B. C. Pressman, R. Gianetto, R. Wattiaux, and F. Appelmans. Tissue fractionation studies. 6. Intracellular distribution patterns of 
enzymes in rat-liver tissue. Biochem. J. 1955, 60 , 604.

15. Arias, I. M. Chronic unconjugated hyperbilirubinemia without overt signs of hemolysis in adolescents and adults. J. clin. Invest. 1962, 41, 2233.

16. Lowry, O. H., N. J. Rosebrough, A. L. Farr, and R. J. Randall. Protein measurement with the folin phenol reagent. J. biol. Chem. 1951, 193, 265.

17. Snedecor, G. W. Statistical Methods Applied to Experiments in Agriculture and Biology. Ames, Iowa State College Press, 1956.

18. Bernstein, L. H. Unpublished observations.
19. Gartner, L. M., and I. M. Arias. Unpublished observations.

20. Weiss, J., and I. M. Arias. Unpublished observations.

21. Goldfischer, S., I. M. Arias, E. Essner, and A. B. Novikoff. Cytochemical and electron microscopic studies of rat liver with reduced capacity to transport conjugated bilirubin. J. exp. Med. 1962, 115, 467.

22. Popper, H., F. Schaffner, E. Rubin, T. Barka, and F. Paronetto. Mechanisms of intrahepatic cholestasis in drug-induced hepatic injury. Ann. N. Y. Acad. Sci. 1963, 104, 988. 